OPEN ACCESS

Edited by:

Arne Møller,

Aarhus University Hospital, Denmark

Reviewed by:

Sarah Jane Baracz, University of New South

Wales, Australia

Briac Halbout,

University of California, Irvine,

United States

*Correspondence:

Kah-Chung Leong

kleong@trinity.edu

Specialty section:

This article was submitted to

Motivation and Reward,

a section of the journal

Frontiers in Behavioral Neuroscience

Received: 05 September 2020

Accepted: 17 November 2020

Published: 15 December 2020

Citation:

Patel D, Sundar M, Lorenz E and

Leong K-C (2020) Oxytocin

Attenuates Expression, but Not

Acquisition, of Sucrose Conditioned

Place Preference in Rats.

Front. Behav. Neurosci. 14:603232.

doi: $10.3389 /$ fnbeh.2020.603232

\section{Oxytocin Attenuates Expression, but Not Acquisition, of Sucrose Conditioned Place Preference in Rats}

\author{
Devon Patel, Megana Sundar, Eva Lorenz and Kah-Chung Leong* \\ Department of Psychology, Trinity University, San Antonio, TX, United States
}

Maladaptation of reward processing for natural rewards, such as sucrose or sugar, may play a role in the development of diseases such as obesity and diabetes. Furthermore, uncovering mechanisms to disrupt or reverse maladaptation of reward-seeking behaviors for natural reinforcers can provide insight into treatment of such diseases, as well as disorders such as addiction. As such, studying the effects of potential pharmacotherapeutics on maladaptive sugar-seeking behavior offers valuable clinical significance. Sucrose conditioned place preference (CPP) paradigms can offer insight into aspects of reward processes as it provides a way to assess acquisition and expression of context-reward associations. The present study examined the effect of peripheral oxytocin injections on sucrose CPP in rats. Oxytocin, when administered prior to CPP test, attenuated expression of sucrose CPP. However, oxytocin, when administered during sucrose conditioning, did not affect subsequent place preference. These findings suggest oxytocin sufficiently attenuates expression of sucrose-associated place preference.

Keywords: oxytocin, sucrose, sugar, reward, conditioned place preference (CPP)

\section{INTRODUCTION}

Overconsumption of sugar has been shown to lead to a myriad of diseases. Excess sugar can lead to an increased risk of developing cardiovascular disease and type 2 diabetes (Stanhope, 2016). This excessive consumption also promotes obesity and increases visceral fat volume, which is associated with risk factors for metabolic disease (Carr et al., 2004). The fact that a wide variety of foods contain added sugar perpetuates the issue. For example, sugar-sweetened beverages, such as fruit juice and soda, account for the primary source of added sugar in the diets of people over the age of 2-years-old in the United States (Bailey et al., 2018). While numerous studies have examined potential therapeutic targets for the treatment of drug-related behaviors and addiction, relatively few studies have examined therapeutic targets that modulate reward behaviors related to natural reinforcers. The present study aimed to examine the effect of a potential therapeutic target, oxytocin, on sucrose-associated place preference behavior.

Oxytocin is a neuropeptide implicated in a variety of behaviors including addictive processes, stress responses, and social affiliations (Lee et al., 2016). Previous experiments have shown that oxytocin affects the seeking and reinstatement behavior to a variety of drugs of abuse, including alcohol (King and Becker, 2019), methamphetamine (Carson et al., 2010), and cocaine (Morales-Rivera et al., 2014; Leong et al., 2016). Early evidence has also demonstrated that oxytocin reduced reinstated sucrose-seeking behavior (Zhou et al., 2015a). Additionally, studies 
have demonstrated that oxytocin attenuated sucrose-seeking behavior and taking behavior in a sex-dependent manner (Cox et al., 2013). Here, we examine whether oxytocin is also effective in disrupting the acquisition and expression of a sucrose-associated place preference.

The conditioned place preference (CPP) paradigm allows experimenters to study context-dependent reward memory and the rewarding value of natural and drug stimuli (Carr et al., 1989; Figlewicz et al., 2001). The paradigm provides an effective method for examining reward processes without necessarily the formation of substantial addictive behaviors while still providing insight into the processes that might precede it. The CPP paradigm has commonly been employed to investigate drug reinforcers, including cocaine (Nomikos and Spyraki, 1988) and methamphetamine (Tuazon et al., 1992). Depending on the reinforcer, CPP can be achieved with a single trial (morphine: Mucha et al., 1982; cocaine: Bardo et al., 1986; methamphetamine: Baracz et al., 2012), or can also be induced after multiple administrations (Nomikos and Spyraki, 1988). Recently, a growing body of literature has demonstrated that CPP is a valuable paradigm to study natural reinforcers as well (Bardo and Bevins, 2000). The CPP paradigm is ideal for investigating the effects of oxytocin administration on the processes related to sucrose reward-related behavior.

The goal of the present study is to evaluate the role of oxytocin in attenuating sucrose-associated place preference through the establishment of sucrose CPP. Although high sucrose consumption is a prevalent cause for many health conditions, pharmacological interventions of sucrose-seeking behavior have not been thoroughly elucidated. Specifically we demonstrate here that administration of peripheral oxytocin prior to expression, but not during conditioning, of sucrose place preference effectively reduces sucrose-associated place preference behavior, indicating that oxytocin is an effective pharmacological option to disrupt sucrose-associated reward behaviors. Potential insights into the use of oxytocin as an option to disrupt maladaptation of reward processes are also discussed.

\section{METHODS}

\section{Subjects}

Adult male (maintained at 275-300 g throughout study) SpragueDawley rats (Charles River Laboratories, $N=35$ ) were used in this study. Rats were single-housed on a reverse 12:12 light-dark cycle in a set temperature and humidity-controlled vivarium. During the experiment, animals were food-restricted to $10 \mathrm{~g}$ of chow daily and water ad-libitum. All procedures were approved by the Institutional Animal Care and Use Committee (IACUC) of Trinity University.

\section{Apparatus}

The CPP apparatus (Panlab-Harvard Apparatus) was composed of two Plexiglas compartments (each: $30.0 \mathrm{~cm}$ length $\times 30.0 \mathrm{~cm}$ width $\times 34.0 \mathrm{~cm}$ height $)$ that were connected by a central corridor $(10.0 \mathrm{~cm}$ length $\times 8.0 \mathrm{~cm}$ width $\times 34.0 \mathrm{~cm}$ height $)$. One compartment had a black floor and walls, while the other compartment had a white floor and walls. The central corridor had gray walls and a gray floor. All floor and wall textures were consistent. The animal's location and transitions between compartments were measured using pressure plates under the floors of the gray and black compartments and the data were relayed to the tracking software, PPCWIN, via a control panel (Panlab-Harvard Apparatus). The doors in between the compartments were manually operated sliding doors.

\section{Drugs}

Oxytocin (Cell Sciences) was dissolved in $0.9 \% \mathrm{NaCl}$ saline and administered intraperitoneally (i.p.) at a dose of $1 \mathrm{mg} / \mathrm{kg}$.

\section{Behavioral Protocol Sucrose Priming}

For 2 days prior to the start of the habituation phase, all rats were food restricted to 10 grams of standard chow and given 10 sucrose pellets (45 mg each, Bio-Serv) each, daily.

\section{Habituation}

Behavioral training began with a habituation trial to determine baseline place preference. No sucrose was provided for the duration of habituation. During habituation, all rats were placed in the gray central corridor. Then, the doors were opened so the animal was allowed free access to both of the compartments for an entire 15-min session. During the session, the amount of time the rat stayed in each compartment was measured and the percentage of time spent within either compartment was calculated to determine the animal's baseline preference. Whichever compartment that the rat did not display greater baseline preference for was designated as the sucrose-paired compartment during subsequent conditioning trials.

\section{Conditioning}

Rats were randomly assigned to the different treatment groups and counterbalanced such that all the rats did not start conditioning in the same compartment each day (i.e., subsequent sessions started in opposite chambers). Animals received three sucrose-paired sessions in the non-preferred compartment on alternate days (e.g., Days 1, 3, 5) and three unpaired sessions on the days in between sucrose-paired sessions. Training sessions ran for 6 consecutive days and lasted 30-min each. During the sucrose conditioning days, animals initially received five sucrose pellets followed by five more every $10 \mathrm{~min}$ (15 pellets total), delivered at regular intervals by the experimenter. Sucrose pellets were consumed in all conditions. On unpaired sessions rats received "sham deliveries," in which the experimenter would make identical movements every $10 \mathrm{~min}$ without the actual delivery of sucrose pellets.

\section{Testing}

On the 7th day (Test Day), animals underwent the same procedure as in habituation to determine if sucrose conditioned place preference had been established. No sucrose was provided for the duration of testing. Depending on the experimental group, the animals either received an injection of saline (VEH) or oxytocin (OXY) test day (described below). 


\section{Experimental Procedures Pre-test Oxytocin (Exp. 1a)}

To determine the effect of oxytocin on the expression of sucroseassociated place preference, all rats underwent sucrose priming, habituation, conditioning, and testing as adapted from Figlewicz et al. (2001) and described above (Figure 1). On day 7 (Test Day), rats were either injected with OXY (1 mg/kg; i.p.; $n=7)$ or VEH ( $n=7) 35 \mathrm{~min}$ prior to testing. The test session was identical to the habituation procedure.

\section{Oxytocin During Conditioning (Exp. 1b)}

To determine the effect of oxytocin on the acquisition of sucrose-associated place preference, all rats underwent identical behavioral procedures as Exp. 1a. Rats either received an injection of OXY ( $1 \mathrm{mg} / \mathrm{kg}$; i.p.; $n=8)$ or VEH $(n=6) 35 \mathrm{~min}$ prior to the start of sucrose-paired sessions during conditioning. All rats also received an injection of VEH $35 \mathrm{~min}$ prior to the start of non-sucrose-paired sessions. No injections were given on test day.

\section{No Manipulation (Exp. 1c)}

To determine that development of any place preference was specifically due to sucrose-associated conditioning, one group of rats $(n=7)$ did not receive sucrose pellets during conditioning. The animals received sucrose pellets only during priming but did not receive any sucrose pellets during behavioral training or test. All rats underwent the same conditioning and testing procedures without drug manipulation.

\section{Statistical Analyses}

Amount of time and percentage of time spent in chambers was calculated using PPCWIN software. Percentage of time spent in the sucrose-paired chamber was calculated as time spent in sucrose-paired chamber/total time spent in black and white chambers. Time spent in the gray chamber was omitted as no time was spent in this chamber during conditioning trials. Two-way repeated measures ANOVAs were performed to determine between-group differences in place preference between OXY and VEH treated animals and within-group differences between baseline and test preference. Post-hoc Sidak's multiple comparisons test were performed to compare differences in time spent in sucrose-paired chambers within habituation or test across treatment groups. All data are presented as the mean \pm S.E.M. and $\alpha$ was set at $p<0.05$.

\section{RESULTS}

\section{Pre-test Oxytocin Disrupts Expression of Sucrose Conditioned Place Preference}

A two-way repeated measures ANOVA revealed a significant main effect of treatment group $\left[F_{(1,12)}=20.94, p<0.01\right]$ and significant main effect of test $\left[F_{(1,12)}=8.059, p<0.05\right]$. There was a statistically significant interaction between the effect of treatment and test on sucrose preference $\left[F_{(1,12)}=17.34\right.$, $p<0.01]$. A post-hoc Sidak's multiple comparisons test revealed a significant difference in time spent in the sucrose-paired chamber during test between OXY $(M=21.01, S D=12.35)$ and $\mathrm{VEH}$
$(M=58.22, S D=9.54 ; p<0.01)$ treated animals but no significant difference between both groups in baseline preference (OXY: $M=26.85, S D=12.35$; $\mathrm{VEH}: M=27.33$, $S D=9.12$; n.s.). These results suggest that OXY treated animals displayed attenuated expression of sucrose-associated place preference relative to $\mathrm{VEH}$ treated animals at test (Figure 2A).

\section{Oxytocin During Conditioning Did Not Affect Acquisition of Sucrose Place Preference}

Animals in Exp. 1b underwent similar behavioral procedures as Exp. 1a except OXY was administered prior to conditioning trials instead of prior to test. A two-way repeated measures ANOVA revealed a significant main effect of test $\left[F_{(1,12)}=18.14, p<\right.$ 0.01]. There was no significant main effect of treatment group $\left[F_{(1,12)}=1.730\right.$, n.s. $]$ and no significant interaction $\left[F_{(1,12)}\right.$ $=0.2431$, n.s.]. A post-hoc Sidak's multiple comparisons test revealed no significant difference in time spent in the sucrose chamber between treatment groups at test (OXY: $M=38.11, S D$ $=15.64$; VEH: $M=47.08, S D=9.67$; n.s.) or baseline (OXY: $M=22.38, S D=11.72$; VEH: $M=27.23, S D=10.63$, n.s.), suggesting that OXY administration during conditioning did not affect acquisition of sucrose-associated place preference relative to VEH treated animals (Figure 2B).

\section{Animals Showed No Change in Baseline Behavior Without Sucrose Conditioning}

In order to determine that place preference behavior was a result of sucrose-pairing during conditioning, rats underwent the same procedure as Exp. 1a and $1 \mathrm{~b}$ without any sucrose-pairings. A paired $t$-test revealed no significant difference in time spent in the sucrose-paired chamber during test $(M=29.23, S D=13.79)$ and baseline preference $[M=19.15, S D=13.16 ; t(6)=1.78$, n.s.; Figure 2C] when animals were not exposed to sucrose-pairings in either chamber. These results suggest that the place preference developed in prior experiments were a result of sucrose-pairings within those chambers.

\section{DISCUSSION}

The present study demonstrates that sucrose conditioned place preference was successfully acquired in animals that received sucrose-pairings in a specific context and that peripheral administration of oxytocin significantly disrupted expression of conditioned place preference when administered before the test. However, oxytocin administered during conditioning trials did not affect the acquisition of sucrose conditioned place preference. These findings suggest that oxytocin sufficiently attenuates expression of sucrose-associated place preference and may be a viable option to disrupt expression of maladaptive sucrose-seeking behaviors.

Oxytocin's effects on reward-seeking behavior for natural and drug reward have been previously documented, with oxytocin reducing alcohol- (King and Becker, 2019), cocaine(Zhou et al., 2015b; Leong et al., 2016; Kohtz et al., 2018; Weber et al., 2018), opioid- (Kovács et al., 1985; Sarnyai and 


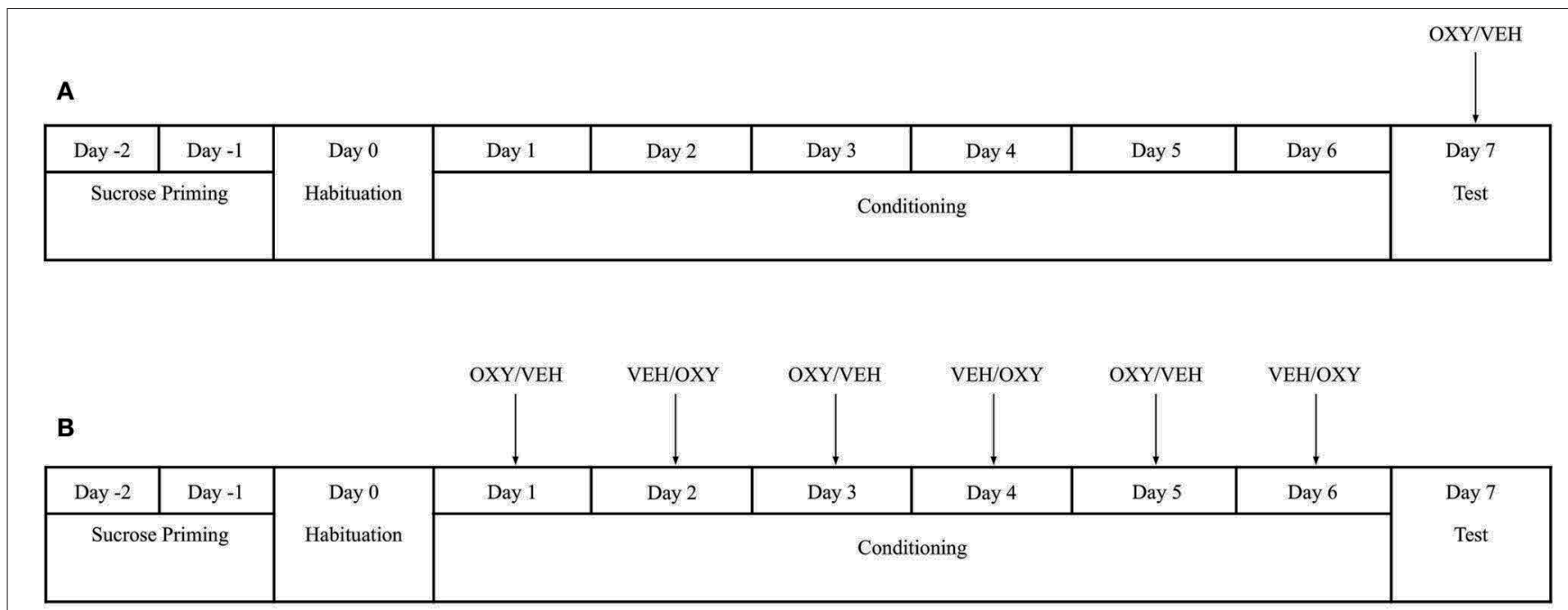

C

\begin{tabular}{|c|c|c|c|c|c|c|c|c|c|}
\hline Day -2 & Day -1 & \multirow{2}{*}{$\begin{array}{c}\text { Day 0 } \\
\text { Habituation }\end{array}$} & Day 1 & Day 2 & Day 3 & Day 4 & Day 5 & Day 6 & \multirow{2}{*}{$\begin{array}{r}\text { Day } 7 \\
\text { Test }\end{array}$} \\
\hline Sucro & riming & & \multicolumn{6}{|c|}{ Conditioning } & \\
\hline
\end{tabular}

FIGURE 1 | Experimental timeline and pharmacological manipulation in (A) Experiment 1a (B) Experiment 1b (C) Experiment 1c. Sucrose-conditioning sessions were counterbalanced in Experiment 1a and 1b. In Experiment 1b, animals in the OXY treatment group received OXY injections only prior to sucrose-paired conditioning sessions. Animals in Experiment 1c received no access to sucrose pellets during conditioning or any injections of OXY or VEH. VEH = Vehicle; OXY $=$ Oxytocin.
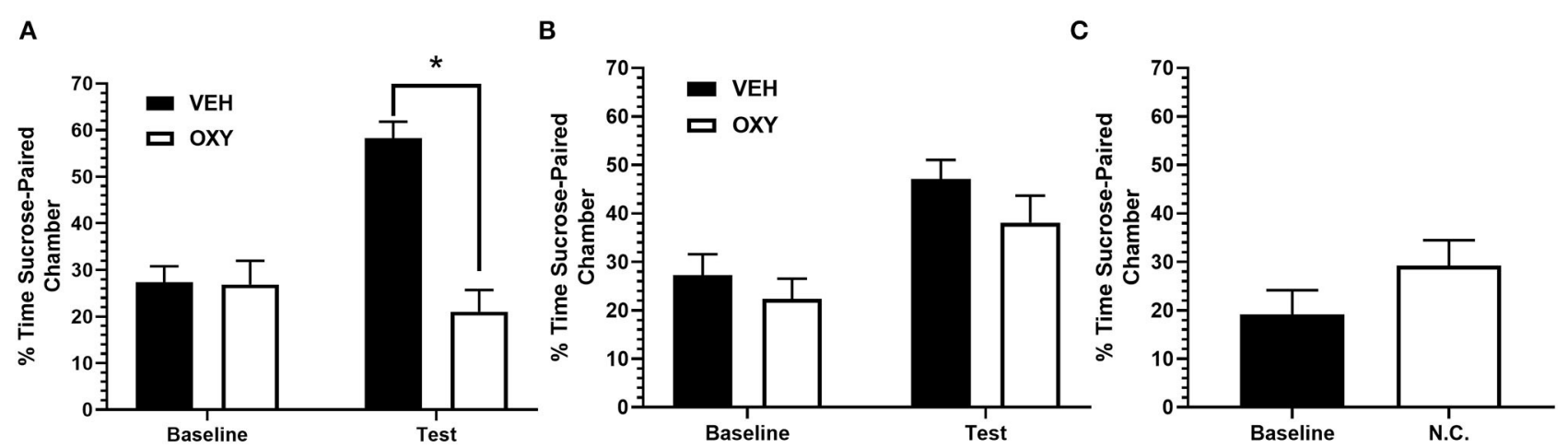

FIGURE 2 | Percentage of time spent in sucrose-paired chamber on test. (A) Rats injected with OXY displayed an attenuation in time spent in the sucrose-paired chamber during preference test relative to VEH treated rats. There was no difference in baseline preference between VEH and OXY treated rats. (B) All rats successfully acquired sucrose-associated conditioned place preference. There was no difference in time spent in sucrose-paired chamber during preference test between OXY or VEH administered during conditioning. (C) Non-conditioned rats, receiving no sucrose-pairings or drug manipulation, spent displayed no difference in time spent in sucrose-paired chamber relative to baseline. VEH $=$ Vehicle; OXY $=$ Oxytocin; N.C. $=$ No conditioning * indicates significant difference at $p<0.05$.

Kovács, 1994; Zanos et al., 2014), and methamphetamine(Carson et al., 2010; Cox et al., 2013, 2017; Everett et al., 2020) seeking behavior, alcohol (Peters et al., 2017) and sugar consumption (Zhou et al., 2015a), craving for marijuana in marijuana-dependent individuals (McRae-Clark et al., 2013), and opioid craving in opioid-dependent individuals (Moeini et al., 2019). Although shown using different paradigms, there is abundant evidence for oxytocin's ability to attenuate drugseeking behaviors. The present study adds to this body of literature suggesting that oxytocin is also capable of inhibiting the expression of reward-context associations once these associations have been established. 
Oxytocin's effects on reward-context associations are likely acting through its well-established interactions with various structures within the reward circuit. The medial pre-frontal cortex (mPFC) has been implicated in the contextual aspects of reward (Haber and Knutson, 2010), possibly through its projections to the dorsal hippocampus (Le Merre et al., 2018). The $\mathrm{mPFC}$ also contains reciprocal glutamatergic (afferent) and dopaminergic (efferent) projections with the ventral tegmental area (VTA; Qi et al., 2009). Oxytocin exerts inhibitory effects within the MPFC via the release of $\gamma$-aminobutyric acid (GABA) from interneurons onto glutamatergic neurons (Qi et al., 2012). Another study also indicated a potential inhibitory role of oxytocin in the mPFC, as peripheral oxytocin attenuated cocaine cue-induced Fos expression (Leong et al., 2017). This oxytocinmediated inhibitory response within the $\mathrm{MPFC}$ has been shown to disrupt stress-induced reinstatement of methamphetamine CPP (Qi et al., 2009). The amygdala has previously been shown to be involved in the consolidation and expression of amphetamineinduced conditioned place preference (Hiroi and White, 1991; Hsu et al., 2002). Furthermore the central amygdala (CeA), specifically, has been implicated in the acquisition (Rezayof et al., 2007; Li et al., 2011) and expression (Li et al., 2011) of morphine CPP. Oxytocin has been found to excite GABAergic interneurons within the CeA to attenuate emotional responses (Huber et al., 2005; Knobloch et al., 2012). It stands to reason that this inhibitory response from oxytocin might disrupt reward-associated conditioned place preference. There are also a number of studies that suggest oxytocin exerts influence directly within the nucleus accumbens (NAc) to modulate rewardseeking behaviors. Previous research has shown that infusion of oxytocin directly into the NAc attenuates methamphetamineseeking behavior (Baracz et al., 2016; Bernheim et al., 2017; Cox et al., 2017). Furthermore, peripheral administration of oxytocin has been found to normalize cued cocaine-induced Fos expression in the NAc, demonstrating a potential normalizing effect of oxytocin (Leong et al., 2017). Oxytocin has also been shown to affect extracellular dopamine levels in the NAc after being injected into the VTA (Melis et al., 2007).

Previous studies have shown that oxytocin disrupted the acquisition of methamphetamine (Baracz et al., 2012) and oxycodone (Fan et al., 2019) conditioned place preference when administered prior to conditioning sessions. The results of the present study show no effect of oxytocin administration during conditioning in acquisition of sucrose conditioned place preference. These differences might be due to natural and drug reward being mediated by overlapping yet distinct neural pathways (Nestler, 2005; Alhadeff et al., 2019), resulting in a differential effect of oxytocin at various stages of rewardseeking behaviors. Furthermore, it is also likely that, unlike drugs of abuse, the relatively lower hedonic and incentive value of sucrose is insufficient for oxytocin to exert an effect during acquisition (Kelley and Berridge, 2002). Interestingly, oxytocin has also been shown to enhance the expression of morphine-induced conditioned place preference, but not acquisition, when injected intracerebroventricularly (Moaddab et al., 2015). While these results may directly conflict with the present findings and findings of previous studies showing an attenuating effect of oxytocin on drug-seeking behavior, it is possible that oxytocin facilitates expression of morphine $\mathrm{CPP}$ due to morphine's effects on endogenous oxytocin signaling (Kovács et al., 1987). Previous studies have shown that expression of oxytocin receptor and $\mu$-opioid receptor in regions such as the central amygdala (CeA) may result in oxytocin-mediated modulation of morphine's effect (Han and $\mathrm{Yu}, 2009$ ). Additionally, oxytocin has been shown to act as a positive allosteric modulator of $\mu$-opioid receptors (Meguro et al., 2018), which might explain the facilitating effect of oxytocin on morphine CPP but not for other drugs of abuse or natural rewards.

Some studies have questioned the ability for peripherallyadministered oxytocin to cross the blood-brain barrier (BBB) (Ermisch et al., 1985; Kang and Park, 2000), although recent studies have suggested otherwise (Neumann et al., 2013). Peripheral administration of oxytocin caused a rapid increase of oxytocin microdialysates measured in the dorsal hippocampus and amygdala (Neumann et al., 2013). In addition, a central administration of an oxytocin receptor antagonist inhibited the effects of peripherally injected oxytocin on heroin selfadministration, morphine tolerance, and cocaine seeking (Sarnyai et al., 1991; Sarnyai and Kovács, 1994). These results suggest that peripheral oxytocin drives behavioral effects through a central mechanism, either by passage through the BBB or through a feed-forward central-release mechanism. For example, peripheral oxytocin suppresses meth-seeking behavior by potentially drive central oxytocin signaling via vagus nerve projections (Everett et al., 2020). Regardless, future studies should examine the effect of centrally-infused oxytocin on sucrose conditioned place preference. Oxytocin has been shown to reduce sucrose and food intake in rats (Zhou et al., 2015a). Both intraperitoneal and intracerebroventricular injection of oxytocin dose-dependently decreased food intake in rats with ad libitum food and food-restricted rats (Arletti et al., 1989, 1990). Similarly, central oxytocin injections have been shown to decrease intake of a sucrose solution (VTA: Mullis et al., 2013; NAc core but not shell: Herisson et al., 2016). Intravenous oxytocin has also been shown to reduce food intake in fooddeprived rats, but showed no effect on intake of a sugar solution (Klockars et al., 2017). While it is possible that oxytocin's anorexic effect may have influenced the ability of oxytocin to attenuate sucrose place preference, particularly when administered during conditioning, we found no reduction in sucrose pellet intake following oxytocin administration in sucrose-paired conditioning sessions. Furthermore, the results and experimental paradigm of our study examine the effect of oxytocin on sucrose-seeking behavior as there is no sucrose present during testing. Therefore, while oxytocin has previously shown to influence food/sucrose-taking behavior, the present study complements this literature by showing oxytocin also influences sucrose-seeking behavior.

Our present findings demonstrate that oxytocin successfully disrupts sucrose conditioned place preference only after conditioning has been successfully established but does not impact the acquisition of conditioned place preference. Several factors might be driving the oxytocin-specific effect 
on sucrose place preference expression. First, previous studies have demonstrated that the hippocampus is a key structure facilitating the formation and expression of conditioned place preference (Rezayof et al., 2003). In particular, dorsal hippocampus CA1 D2 receptors have been implicated in the expression of drug-associated conditioned place preference (Haghparast et al., 2013; but see Maldonado et al., 1997). A number of studies have suggested that oxytocin interacts with D2 signaling within the hippocampus (Lazzari et al., 2019). Oxytocin receptors are located on GABAergic interneurons within the dorsal hippocampus (Zaninetti and Raggenbass, 2000). These GABAergic interneurons mediate D2-mediated signaling within the hippocampus (Yoon et al., 2015) and it stands to reason that oxytocin might exert its effect on D2 receptor signaling, and thus expression of place preference, via this circuit. Alternatively, the opioid system has been implicated in the expression, but not acquisition, of conditioned place preference of natural reinforcers (Mehrara and Baum, 1990). The opioid component of neural reward circuits is further supported in studies demonstrating that the $\mu$-opioid receptor agonist, buprenorphine, attenuates expression of cocaine conditioned place preference (Kosten et al., 1991; Suzuki et al., 1992). A number of studies have investigated oxytocin's interactions with the $\mu$-opioid receptor. For example, oxytocin-induced nociception is blocked by intra-NAc infusion of $\mu$-opioid receptor antagonist ( $\mathrm{Gu}$ and $\mathrm{Yu}, 2007$ ). Therefore, oxytocin's effect on expression of conditioned place preference could also be driven by its interaction with the endogenous opioid system.

Previous studies have shown that oxytocin produces sexspecific differences in natural and drug related reward-seeking behaviors (Cox et al., 2013; Zhou et al., 2015a; Leong et al., 2016) and that oxytocin receptor expression in the brain show sex-specific differences (Dumais and Veenema, 2016). These studies highlight that the oxytocin system and the behaviors it modulates may be sexually dimorphic and that efforts should be made to directly compare effects of oxytocin between males and females. While the present study investigated the effect of oxytocin on sucrose-seeking behavior in male rats, we used a dose of oxytocin $(1 \mathrm{mg} / \mathrm{kg})$ that has been shown to effectively reduce sucrose reinstatement in males and females (Zhou et al., 2015a).

\section{REFERENCES}

Alhadeff, A. L., Goldstein, N., Park, O., Klima, M. L., Vargas, A., and Betley, J. N. (2019). Natural and drug rewards engage distinct pathways that converge on coordinated hypothalamic and reward circuits. Neuron 103, 891-908. doi: 10.1016/j.neuron.2019.05.050

Arletti, R., Benelli, A., and Bertolini, A. (1989). Influence of oxytocin on feeding behavior in the rat. Peptides 10, 89-93. doi: 10.1016/0196-9781(89)90082-X

Arletti, R., Benelli, A., and Bertolini, A. (1990). Oxytocin inhibits food and fluid intake in rats. Physiol. Behav. 48, 825-830. doi: 10.1016/0031-9384(90)90234-U

Bailey, R. L., Fulgoni, V. L., Cowan, A. E., and Gaine, P. C. (2018). Sources of added sugars in young children, adolescents, and adults with low and high intakes of added sugars. Nutrients 10:102. doi: 10.3390/nu10010102

Baracz, S. J., Everett, N. A., McGregor, I. S., and Cornish, J. L. (2016). Oxytocin in the nucleus accumbens core reduces reinstatement of methamphetamineseeking behaviour in rats: oxy, NAc and METH self-admin. Addict. Biol. 21, 316-325. doi: 10.1111/adb. 12198
However, future studies should examine the effect of oxytocin in sucrose conditioned place preference in females as well.

In conclusion, the present study demonstrates that oxytocin can sufficiently reduce expression of sucrose-mediated conditioned place preference. Further studies should be carried out to determine the specific structures and mechanisms involved in this process. The results presented here provide clinical significance, given the health risks associated with excessive sugar consumption. Furthermore, these results provide additional insight into the processes that underlie oxytocin's effect on reward-related maladaptive behaviors.

\section{DATA AVAILABILITY STATEMENT}

The raw data supporting the conclusions of this article will be made available by the authors, without undue reservation.

\section{ETHICS STATEMENT}

The animal study was reviewed and approved by Institutional Animal Care and Use Committee (IACUC) of Trinity University.

\section{AUTHOR CONTRIBUTIONS}

K-CL, DP, MS, and EL conceived, designed, and performed the experiments. K-CL and DP analyzed the data. K-CL, DP, MS, and EL wrote and edited the manuscript. All authors contributed to the article and approved the submitted version.

\section{FUNDING}

This work was supported by Trinity University Start-Up Funds (K-CL).

\section{ACKNOWLEDGMENTS}

We would like to thank Rodrigo Castillo for his contribution in collecting pilot data and equipment troubleshooting. We would like to thank Hannah Ballas, Alyssa Avalos, and Amia Cressman for collection of additional data.
Baracz, S. J., Rourke, P. I., Pardey, M. C., Hunt, G. E., McGregor, I. S., and Cornish, J. L. (2012). Oxytocin directly administered into the nucleus accumbens core or subthalamic nucleus attenuates methamphetamine-induced conditioned place preference. Behav. Brain Res. 228, 185-193. doi: 10.1016/j.bbr.2011. 11.038

Bardo, M. T., and Bevins, R. A. (2000). Conditioned place preference: what does it add to our preclinical understanding of drug reward? Psychopharmacology 153, 31-43. doi: 10.1007/s002130000569

Bardo, M. T., Neisewander, J. L., and Miller, J. S. (1986). Repeated testing attenuates conditioned place preference with cocaine. Psychopharmacology 89, 239-243. doi: 10.1007/BF00310636

Bernheim, A., Leong, K.-C., Berini, C., and Reichel, C. M. (2017). Antagonism of MGlu2/3 receptors in the nucleus accumbens prevents oxytocin from reducing cued methamphetamine seeking in male and female rats. Pharmacol. Biochem. Behav. 161, 13-21. doi: 10.1016/j.pbb.2017.08.012

Carr, D. B., Utzschneider, K. M., Hull, R. L., Kodama, K., Retzlaff, B. M., Brunzell, J. D., et al. (2004). Intra-abdominal fat is a major determinant of the 
national cholesterol education program adult treatment panel III criteria for the metabolic syndrome. Diabetes 53, 2087-2094. doi: 10.2337/diabetes.53.8.2087

Carr, G. D., Fibiger, H. C., and Phillips, A. G. (1989). "Conditioned place preference as a measure of drug reward," in The Neuropharmacological Basis of Reward. Topics in Experimental Psychopharmacology 1, eds J. M. Liebman and S. J. Cooper (New York, NY: Clarendon Press/Oxford University Press), 264-319.

Carson, D. S., Cornish, J. L., Guastella, A. J., Hunt, G. E., and McGregor, I. S. (2010). Oxytocin decreases methamphetamine self-administration, methamphetamine hyperactivity, and relapse to methamphetamine-seeking behaviour in rats. Neuropharmacology 58, 38-43. doi: 10.1016/j.neuropharm.2009.06.018

Cox, B. M., Bentzley, B. S., Regen-Tuero, H. R. E., Reichel, C. M., and Aston-Jones, G. (2017). Oxytocin acts in nucleus accumbens to attenuate methamphetamine seeking and demand. Biol. Psychiatry 81, 949-958. doi: 10.1016/j.biopsych.2016.11.011

Cox, B. M., Young, A. B., See, R. E., and Reichel, C. M. (2013). Sex differences in methamphetamine seeking in rats: impact of oxytocin. Psychoneuroendocrinology 38, 2343-2353. doi: 10.1016/j.psyneuen.2013.05.005

Dumais, K. M., and Veenema, A. H. (2016). Vasopressin and oxytocin receptor systems in the brain: sex differences and sex-specific regulation of social behavior. Front. Neuroendocrinol. 40:1-23. doi: 10.1016/j.yfrne.2015.04.003

Ermisch, A., Rühle, H. J., Landgraf, R., and Hess, J. (1985). Bloodbrain barrier and peptides. J. Cereb. Blood Flow Metab. 5, 350-357. doi: $10.1038 /$ jcbfm. 1985.49

Everett, N. A., Turner, A. J., Costa, P. A., Baracz, S. J., and Cornish, J. L. (2020). The vagus nerve mediates the suppressing effects of peripherally administered oxytocin on methamphetamine self-administration and seeking in rats. Neuropsychopharmacology. doi: 10.1038/s41386-020-0719-7. [Epub ahead of print].

Fan, X.-Y., Shi, G., and Zhao, P. (2019). Reversal of oxycodone conditioned place preference by oxytocin: promoting global dna methylation in the hippocampus. Neuropharmacology 160:107778. doi: 10.1016/j.neuropharm.2019.107778

Figlewicz, D. P., Higgins, H. S., Ng-Evans, S. B., and Havel, P. J. (2001). Leptin reverses sucrose-conditioned place preference in food-restricted rats. Physiol. Behav. 73, 229-234. doi: 10.1016/S0031-9384(01)00486-3

$\mathrm{Gu}, \mathrm{X}$.-L., and Yu, L.-C. (2007). Involvement of opioid receptors in oxytocininduced antinociception in the nucleus accumbens of rats. J. Pain 8, 85-90. doi: 10.1016/j.jpain.2006.07.001

Haber, S. N., and Knutson, B. (2010). The reward circuit: linking primate anatomy and human imaging. Neuropsychopharmacology 35, 4-26. doi: 10.1038/npp.2009.129

Haghparast, A., Esmaeili, M.-H., Taslimi, Z., Kermani, M., Yazdi-Ravandi, S., and Alizadeh, A.-M. (2013). Intrahippocampal administration of D2 but not D1 dopamine receptor antagonist suppresses the expression of conditioned place preference induced by morphine in the ventral tegmental area. Neurosci. Lett. 541, 138-143. doi: 10.1016/j.neulet.2013.03.001

Han, Y., and Yu, L.-C. (2009). Involvement of oxytocin and its receptor in nociceptive modulation in the central nucleus of amygdala of rats. Neurosci. Lett. 454, 101-104. doi: 10.1016/j.neulet.2009.02.062

Herisson, F. M., Waas, J. R., Fredriksson, R., Schiöth, H. B., Levine, A. S., and Olszewski, P. K. (2016). Oxytocin acting in the nucleus accumbens core decreases food intake. J. Neuroendocrinol. 28:e12381. doi: 10.1111/jne.12381

Hiroi, N., and White, N. M. (1991). The amphetamine conditioned place preference: differential involvement of dopamine receptor subtypes and two dopaminergic terminal areas. Brain Res. 552, 141-152. doi: 10.1016/0006-8993(91)90672-I

Hsu, E. H., Schroeder, J. P., and Packard, M. G. (2002). The amygdala mediates memory consolidation for an amphetamine conditioned place preference. Behav. Brain Res. 129, 93-100. doi: 10.1016/S0166-4328(01)00376-X

Huber, D., Venante, P., and Stoop, R. (2005). Vasopressin and oxytocin excite distinct neuronal populations in the Central Amygdala. Science 308, 245-248. doi: $10.1126 /$ science. 1105636

Kang, Y.-S., and Park, J.-H. (2000). Brain uptake and the analgesic effect of oxytocin-its usefulness as an analgesic agent. Arch. Pharm. Res. 23, 391-395. doi: 10.1007/BF02975453

Kelley, A. E., and Berridge, K. C. (2002). The neuroscience of natural rewards: relevance to addictive drugs. J. Neurosci. 22, 3306-3311. doi: 10.1523/JNEUROSCI.22-09-03306.2002
King, C. E., and Becker, H. C. (2019). Oxytocin attenuates stress-induced reinstatement of alcohol seeking behavior in male and female mice. Psychopharmacology 6, 2613-2622. doi: 10.1007/s00213-019-05233-Z

Klockars, A., Brunton, C., Li, L., Levine, A. S., and Olszewski, P. K. (2017). Intravenous administration of oxytocin in rats acutely decreases deprivationinduced chow intake, but it fails to affect consumption of palatable solutions. Peptides 93, 13-19. doi: 10.1016/j.peptides.2017.04.010

Knobloch, H. S., Charlet, A., Hoffmann, L. C., Eliava, M., Khrulev, S., Cetin, A. H., et al. (2012). Evoked axonal oxytocin release in the central amygdala attenuates fear response. Neuron 73, 553-566. doi: 10.1016/j.neuron.2011.11.030

Kohtz, A. S., Lin, B., Smith, M. E., and Aston-Jones, G. (2018). Attenuated cocaine-seeking after oxytocin administration in male and female rats. Psychopharmacology 235, 2051-2063. doi: 10.1007/s00213-018-4902-Z

Kosten, T. A., Marby, D. W., and Nestler, E. J. (1991). Cocaine conditioned place preference is attenuated by chronic buprenorphine treatment. Life Sci. 49, PL201-PL206. doi: 10.1016/0024-3205(91)90490-3

Kovács, G. L., Borthaiser, Z., and Telegdy, G. (1985). Oxytocin reduces intravenous heroin self-administration in heroin-tolerant rats. Life Sci. 37, 17-26. doi: 10.1016/0024-3205(85)90620-4

Kovács, G. L., Laczi, F., Vecsernyés, M., Hódi, K., Telegdy, G., and László, F. A. (1987). Limbic oxytocin and arginine8-vasopressin in morphine tolerance and dependence. Experim. Brain Rese. 65, 307-311. doi: 10.1007/BF00236302

Lazzari, V. M., Zimmermann-Peruzatto, J. M., Agnes, G., Becker, R. O., de Moura, A. C., and Almeida, S. (2019). Hippocampal gene expression patterns in oxytocin male knockout mice are related to impaired social interaction. Behav. Brain Res. 364, 464-468. doi: 10.1016/j.bbr.2017.10.034

Le Merre, P., Esmaeili, V., Charrière, E., Galan, K., Salin, P.-A., Petersen, C. C. H., et al. (2018). Reward-based learning drives rapid sensory signals in medial prefrontal cortex and dorsal hippocampus necessary for goal-directed behavior. Neuron 97, 83-91. doi: 10.1016/j.neuron.2017.11.031

Lee, M. R., Rohn, M. C. H., Tanda, G., and Leggio, L. (2016). Targeting the oxytocin system to treat addictive disorders: rationale and progress to date. CNS Drugs 30, 109-123. doi: 10.1007/s40263-016-0313-z

Leong, K.-C., Freeman, L. R., Berini, C. R., Ghee, S. M., See, R. E., and Reichel, C. M. (2017). Oxytocin reduces cocaine cued fos activation in a regionally specific manner. Int. J. Neuropsychopharmacol. 20, 844-854. doi: 10.1093/ijnp/pyx058

Leong, K.-C., Zhou, L., Ghee, S. M., See, R. E., and Reichel, C. M. (2016). Oxytocin decreases cocaine taking, cocaine seeking, and locomotor activity in female rats. Exp. Clin. Psychopharmacol. 24, 55-64. doi: 10.1037/pha0000058

Li, F., Wang, X.-S., Dai, R.-S., Zhang, J.-Y., Zhou, X.-F., Hao, W., et al. (2011). The activation of NMDA receptor-ERK pathway in the central amygdala is required for the expression of morphine-conditioned place preference in the rat. Neurotox. Res. 20, 362-371. doi: 10.1007/s12640-011-9250-2

Maldonado, R., Saiardi, A., Valverde, O., Samad, T. A., Roques, B. P., and Borrelli, E. (1997). Absence of opiate rewarding effects in mice lacking dopamine D2 receptors. Nature 388, 586-589. doi: 10.1038/41567

McRae-Clark, A. L., Baker, N. L., Moran-Santa Maria, M., and Brady, K. T. (2013). Effect of oxytocin on craving and stress response in marijuanadependent individuals: a pilot study. Psychopharmacology 228, 623-631. doi: 10.1007/s00213-013-3062-4

Meguro, Y., Miyano, K., Hirayama, S., Yoshida, Y., Ishibashi, N., Ogino, T., et al. (2018). Neuropeptide oxytocin enhances $\mu$ opioid receptor signaling as a positive allosteric modulator. J. Pharmacol. Sci. 137, 67-75. doi: 10.1016/j.jphs.2018.04.002

Mehrara, B. J., and Baum, M. J. (1990). Naloxone disrupts the expression but not the acquisition by male rats of a conditioned place preference response for an oestrous female. Psychopharmacology 101, 118-125. doi: 10.1007/BF02253728

Melis, M. R., Melis, T., Cocco, C., Succu, S., Sanna, F., Pillolla, G., et al. (2007). Oxytocin injected into the ventral tegmental area induces penile erection and increases extracellular dopamine in the nucleus accumbens and paraventricular nucleus of the hypothalamus of male rats: ventral tegmental area, oxytocin and penile erection. Eur. J. Neurosci. 26, 1026-1035. doi: 10.1111/j.1460-9568.2007.05721.x

Moaddab, M., Hyland, B. I., and Brown, C. H. (2015). Oxytocin enhances the expression of morphine-induced conditioned place preference in rats. Psychoneuroendocrinology 53, 159-169. doi: 10.1016/j.psyneuen.2015. 01.003 
Moeini, M., Omidi, A., Sehat, M., and Banafshe, H. R. (2019). The effects of oxytocin on withdrawal, craving and stress response in heroin-dependent patients: a randomized, double-blind clinical trial. Eur. Addict. Res. 25, 41-47. doi: $10.1159 / 000496194$

Morales-Rivera, A., Hernández-Burgos, M. M., Martínez-Rivera, A., Pérez-Colón, J., Rivera, R., Montalvo, R., et al. (2014). Anxiolytic effects of oxytocin in cueinduced cocaine seeking behavior in rats. Psychopharmacology 231, 4145-4155. doi: 10.1007/s00213-014-3553-y

Mucha, R. F., Van Der Kooy, D., O’Shaughnessy, M., and Bucenieks, P. (1982). Drug reinforcement studied by the use of place conditioning in rat. Brain Res. 243, 91-105. doi: 10.1016/0006-8993(82)91123-4

Mullis, K., Kay, K., and Williams, D. L. (2013). Oxytocin action in the ventral tegmental area affects sucrose intake. Brain Res. 1513, 85-91. doi: 10.1016/j.brainres.2013.03.026

Nestler, E. J. (2005). Is there a common molecular pathway for addiction? Nat. Neurosci. 8, 1445-1449. doi: 10.1038/nn1578

Neumann, I. D., Maloumby, R., Beiderbeck, D. I., Lukas, M., and Landgraf, R. (2013). Increased brain and plasma oxytocin after nasal and peripheral administration in rats and mice. Psychoneuroendocrinology 38, 1985-1993. doi: 10.1016/j.psyneuen.2013.03.003

Nomikos, G. G., and Spyraki, C. (1988). Cocaine-induced place conditioning: importance of route of administration and other procedural variables. Psychopharmacology 94, 119-125. doi: 10.1007/BF00735892

Peters, S. T., Bowen, M. T., Bohrer, K., McGregor, I. S., and INeumann, I. D. (2017). Oxytocin inhibits ethanol consumption and ethanol-induced dopamine release in the nucleus accumbens: oxytocin, ethanol and dopamine. Addict. Biol. 22, 702-711. doi: 10.1111/adb.12362

Qi, J., Han, W.-Y., Yang, J.-Y., Wang, L.-H., Dong, Y.-X., Wang, F., et al. (2012). Oxytocin regulates changes of extracellular glutamate and GABA levels induced by methamphetamine in the mouse brain. Addict. Biol. 17, 758-769. doi: 10.1111/j.1369-1600.2012.00439.x

Qi, J., Yang, J.-Y., Wang, W., Zhao, Y.-N., Song, M., and Wu, C.-F. (2009). Effects of oxytocin on methamphetamine-induced conditioned place preference and the possible role of glutamatergic neurotransmission in the medial prefrontal cortex of mice in reinstatement. Neuropharmacology 56, 856-865. doi: 10.1016/j.neuropharm.2009.01.010

Rezayof, A., Golhasani-Keshtan, F., Haeri-Rohani, A., and Zarrindast, M.-R. (2007). Morphine-induced place preference: involvement of the Central Amygdala NMDA receptors. Brain Res. 1133, 34-41. doi: 10.1016/j.brainres.2006.11.049

Rezayof, A., Zarrindast, M. R., Sahraei, H., and Haeri-Rohani, A. (2003). Involvement Of dopamine receptors of the dorsal hippocampus on the acquisition and expression of morphine-induced place preference in rats. J. Psychopharmacol. 17, 415-423. doi: 10.1177/02698811031 74005

Sarnyai, Z., Babarczy, E., Kriván, M., Szabó, G., Kovács, G. L., Barth, T., et al. (1991). Selective attenuation of cocaine-induced stereotyped behaviour by oxytocin: putative role of basal forebrain target sites. Neuropeptides 19, 51-56. doi: 10.1016/0143-4179(91)90073-R
Sarnyai, Z., and Kovács, G. L. (1994). Role of oxytocin in the neuroadaptation to drugs of abuse. Psychoneuroendocrinology 19, 85-117. doi: 10.1016/0306-4530(94)90062-0

Stanhope, K. L. (2016). Sugar consumption, metabolic disease and obesity: the state of the controversy. Crit. Rev. Clin. Lab. Sci. 53, 52-67. doi: 10.3109/10408363.2015.1084990

Suzuki, T., Shiozaki, Y., Masukawa, Y., Misawa, M., and Nagase, H. (1992). The role of mu- and kappa-opioid receptors in cocaine-induced conditioned place preference. Japan. J. Pharmacol. 58, 435-442. doi: 10.1254/jjp.58.435

Tuazon, D. B., Suzuki, T., Misawa, M., and Watanabe, S. (1992). Methylxanthines (Caffeine and Theophylline) blocked methamphetamine-induced conditioned place preference in mice but enhanced that induced by cocaine. Ann. N. Y. Acad. Sci. 654, 531-533. doi: 10.1111/j.1749-6632.1992.tb26022.x

Weber, R. A., Logan, C. N., Leong, K.-C., Peris, J., Knackstedt, L., and Reichel, C. M. (2018). Regionally specific effects of oxytocin on reinstatement of cocaine seeking in male and female rats. Int. J. Neuropsychopharmacol. 21, 677-686. doi: 10.1093/ijnp/pyy025

Yoon, D. H., Yoon, S., Kim, D., Kim, H., and Baik, J. H. (2015). Regulation of dopamine D2 receptor-mediated extracellular signal-regulated kinase signaling and spine formation by GABAA receptors in hippocampal neurons. Neurosci. Lett. 586, 24-30. doi: 10.1016/j.neulet.2014.12.010

Zaninetti, M., and Raggenbass, M. (2000). Oxytocin receptor agonists enhance inhibitory synaptic transmission in the rat hippocampus by activating interneurons in stratum pyramidale: oxytocin action in the hippocampus. Eur. J. Neurosci. 12, 3975-3984. doi: 10.1046/j.1460-9568.2000.00290.x

Zanos, P., Georgiou, P., Wright, S. R., Hourani, S. M., Kitchen, I., WinskySommerer, R., et al. (2014). The oxytocin analogue carbetocin prevents emotional impairment and stress-induced reinstatement of opioid-seeking in morphine-abstinent mice. Neuropsychopharmacology 39, 855-865. doi: 10.1038/npp.2013.285

Zhou, L., Ghee, S. M., See, R. E., and Reichel, C. M. (2015a). Oxytocin differentially affects sucrose taking and seeking in male and female rats. Behav. Brain Res. 283, 184-190. doi: 10.1016/j.bbr.2015.01.050

Zhou, L., Sun, W.-L., Young, A. B., Lee, K., McGinty, J. F., and See, R. E. (2015b). Oxytocin Reduces cocaine seeking and reverses chronic cocaineinduced changes in glutamate receptor function. Int. J. Neuropsychopharmacol. 18, pyu009-pyu009. doi: 10.1093/ijnp/pyu009

Conflict of Interest: The authors declare that the research was conducted in the absence of any commercial or financial relationships that could be construed as a potential conflict of interest.

Copyright (c) 2020 Patel, Sundar, Lorenz and Leong. This is an open-access article distributed under the terms of the Creative Commons Attribution License (CC BY). The use, distribution or reproduction in other forums is permitted, provided the original author(s) and the copyright owner(s) are credited and that the original publication in this journal is cited, in accordance with accepted academic practice. No use, distribution or reproduction is permitted which does not comply with these terms. 